\begin{tabular}{|c|c|c|c|c|c|}
\hline MUNIBE Antropologia-Arkeologia & $\mathrm{n}^{\circ} 68$ & $101-113$ & DONOSTIA & 2017 & ISSN 1132-2217 • elSSN 2172-4555 \\
\hline
\end{tabular}

\title{
Una destacada adición accidental al arte mobiliar magdaleniense de la Cueva de La Paloma (Las Regueras, Asturias)
}

\author{
A prominent accidental addition to the Magdalenian portable \\ art of the cave of La Paloma (Las Regueras, Asturias)
}

PALABRAS CLAVES: arte mueble magdaleniense, representaciones de renos, signos lineales, fecha radiocarbónica, Cueva de la Paloma, Asturias. GAKO-HITZAK: Madelein aldiko arte mugigarria, elu-oreinen errepresentazioak, lerroen zeinuak, data erradiokarbonikoa, Paloma leizea, Asturias. KEY WORDS: Magdalenian portable art, representations of reindeers, linear signs, ${ }^{14} \mathrm{C}$ date, Cueva de la Paloma, Asturias.

\section{Miguel Ángel DE BLAS CORTINA ${ }^{(1)}$ y Carlos BRIANSÓ(2)}

\section{A Ignacio Barandiaran Maestu \\ RESUMEN}

El hallazgo de dos nuevas piezas de arte mueble en la Cueva de la Paloma incrementa la calidad del valioso repertorio recuperado durante las excavaciones de 1914 y 1915. Sobre un tallo y una punta, ambos de asta de ciervo, se observan las figuras grabadas de tres renos, una cabra, y un cérvido incierto, además de signos lineales.

El análisis técnico, formal y estilístico de las representaciones permite su asignación al magdaleniense superior, estimación respaldada por la fecha $\mathrm{C}^{14}$ (AMS) del tallo. Los animales elegidos y ciertas sugerencias formales en los mismos dan pie a distintas consideraciones de naturaleza etológica, así como la atención a la presencia de Rangifer tarandus en el sector centro-occidental de la región cantábrica durante los episodios climáticos más rigurosos a finales del paleolítico superior.

\section{LABURPENA}

Paloma leizean arte mugigarriaren beste bi pieza topatu izanak handitu egiten du 1914 eta 1915eko indusketetan berreskuratutako errepertorio baliotsuaren kalitatea. Zurtoin eta punta baten gainean (biak orein adarrarenak), hiru elur-oreinen, ahuntz baten eta oreinaren familiako ezezagun baten irudiak daude grabatuta, zeinu linealez gain.

Errepresentazioen azterketa tekniko, formal eta estilistikoari esker, Goi Madelein aldikoak direla esan daiteke, eta hori berresten du zurtoinari egindako $\mathrm{C}^{14}(\mathrm{AMS})$ datak. Aukeratutako animaliak eta horietan dauden iradokizun formal batzuk kontuan hartuta, izaera etologikoko zenbait ohar egin ditzakegu. Bestalde, deigarria da goi-paleolitikoaren amaierako aldi klimatiko zorrotzenetan kantauriar eskualdeko erdiko-mendebaldeko sektorean Rangifer tarandus agertzea ere.

\section{ABSTRACT}

The finding of two new pieces of portable art in the Cueva de la Paloma increases the quality of the valuable collection recovered during the excavations of 1914 and 1915. Besides linear signs, the engraved figures of three reindeers, a goat and an uncertain cervidae are observed on a stem and on a top made out of shaft of deer.

The technical, formal and stylistic analysis of the representations allows his assignment to the top magdalenian, estimation supported by the date ${ }^{14} \mathrm{C}$ (AMS) of the stem. The chosen animals and certain formal suggestions in the same ones lead to different considerations of ethological nature, as well as the attention to the presence of Rangifer tarandus in the western sector of the Cantabrian region during the most rigorous climatic episodes at the end of the Upper Paleolithic.

\section{1.- INTRODUCCIÓN}

La Cueva de la Paloma, o de los Palombos en la olvidada toponimia local, fue una de las cavernas cantábricas con asentamiento paleolítico investigadas en fecha temprana. Una primera campaña en el verano de 1914, y otra más breve en 1915, permitieron constatar la importancia de un yacimiento cuya potente estratigrafía testimoniaba la prolongada ocupación humana a lo largo de los sucesivos ciclos magdalenienses y con un claro episodio aziliense, además de la certificación de estadios prehistóricos posteriores, cuyos continentes sedimentarios habían sido revueltos y alterados por la serie de incidentes sufridos modernamente por el yacimiento.

De la existencia de elementos mobiliares con representaciones de animales dio noticia escueta inicial

\footnotetext{
(1) Dpto. de Historia (Prehistoria). Universidad de Oviedo; deblas@uniovi.es

(2) carlos.brianso1@gmail.com
} 
uno de los excavadores, J. Cabré, aportando el dibujo de una varilla ósea con la representación grabada de un équido atribuida entonces al magdaleniense inferior (Cabré, 1915: 25 y fig. 27), asunto obviamente tratado de forma más extensa, aunque muy parcial, en el estudio de la caverna firmado por E. Hernández Pacheco, trabajo de síntesis redactado en principio como aportación al Libro de honor ofrecido a Santiago Ramón y Cajal con motivo de su jubilación como catedrático de la Universidad de Madrid. El prestigioso Nobel en Medicina era presidente de la Junta para la Ampliación de Estudios de la que dependía la Comisión de Investigaciones Prehistóricas y Paleontológicas (habitualmente aludida por su acrónimo CIPP) dirigida por el propio Hernández Pacheco, circunstancia que explica que Ramón y Cajal viajara a Asturias en 1914 para acompañar en una jornada a los excavadores de la caverna cercana al río Nalón.

El artículo del aludido homenaje fue reeditado en forma de monografía en las series de la Comisión, reproduciendo su forma de ensayo sobre la vida de los paleolíticos, enfoque que vino a determinar la escueta exposición, tanto de la secuencia estratigráfica como del número y diversidad de los elementos instrumentales recuperados en la gruta (Hernández-Pacheco, 1923 a). De la calidad del arte mobiliar de La Paloma fue destacada entonces una plaqueta de pizarra en la que, confundidos con numerosas líneas incisas, se inscribían las figuras espléndidas de dos caballos, obra asignada, según su posición contextual, al magdaleniense medio. Del mismo asunto trataría también en la Revue Anthropologique (Hernández-Pacheco, 1922) y, monográficamente, sobre un canto de pizarra en el que la forma de la piedra y los trazos grabados compondrían la cabeza de un caballo a la que se superponían signos no realistas, conjunto gráfico que valoró como esotérico (Hernández-Pacheco, 1923 b).

En la memoria de la CIPP aludía genéricamente a huesos grabados con diversas figuras de animales, a veces varillas y azagayas como soportes, junto con arpones decorados, etc., señalando la sucesión de los hallazgos a lo largo de una rica secuencia magdaleniense que para el autor constituía en aquel momento "el conjunto paleolítico-arqueológico más importante de esta época que hasta el presente existe en España". Sin embargo, la parquedad informativa de la breve monografía dejaba por explicar buena parte de lo existente e investigado, ausencia de detalles que animó las dudas sobre la interpretación estratocultural del yacimiento expresadas a renglón seguido por $\mathrm{H}$. Obermaier (1925: 190-191).

Tal estado de conocimiento sobre La Paloma, inéditos la mayoría de los materiales descubiertos, se mantuvo durante décadas hasta que I. Barandiarán realizara una aproximación a los depositados en el Museo de Ciencias Naturales de Madrid, organismo que había acogido desde su fundación a la aludida CIPP, optando en su análisis por el instrumental en hueso dada su mayor seguridad de atribución cultural que el utillaje de piedra. Siguiendo el guión estratigráfico señalado por el excavador de 1915-1915, concluiría en la distinción de dos episodios paleolíticos: uno magdaleniense inferior cantábrico y otro del magdaleniense final-aziliense inferior (Barandiaran, 1971). Del mismo año es el estudio de algunos de aquellos objetos acometido por $\mathrm{M}^{\mathrm{a}}$ S. Corchón (1971). Nueve años más tarde la revisión de los diarios de Hernández Pacheco y de todos los materiales conservados en el museo aludido significó, junto con el estudio de los procesos sedimentarios determinantes de la formación estratigráfica y de los restos faunísticos asociados, una primera visión general del yacimiento y el catálogo de los restos industriales, desde los productos líticos hasta los cerámicos de los revueltos niveles de ocupación postpaleolítica (Hoyos-Gómez et al., 1980). En el inventario del instrumental en hueso se anota como novedad, con respecto a lo que Barandiaran viera, la "composición realista de dos cabezas de renos" asignable al magdaleniense VI.

En el intermedio entre unas y otras actualizaciones de lo recuperado en la caverna fue incrementado el repertorio por el hallazgo accidental en la misma, en zonas removidas por buscadores esporádicos, de una costilla con el grabado de una cierva y un fragmento de candil de ciervo con la cabeza grabada de un équido, junto con algún otro material óseo (Pérez-Pérez 1975). Además, como documento de asignación incierta, fue consignado un cúbito de águila en el que se inscriben dos cabezas de probables renos, estilísticamente atribuidas a fases avanzadas del magdaleniense. La pieza, de innegable singularidad, fue reencontrada en el Museo de Ciencias Naturales sin que se pudiera establecer si su procedencia era La Paloma o, por el contrario, La Cuevona de Ribadesella. El hecho de que, al contrario que en la ilustre gruta del Nalón, no se sepa de niveles del magdaleniense superior en el yacimiento de la desembocadura del Sella abogaría por La Paloma como origen de un notable testimonio del arte mobiliar (Chapa-Brunet y Martínez-Navarrete 1977). En fin, un último corpus detallado de todas manifestaciones mobiliares de La Paloma, segmentado en los cuatro apartados relativos a las fases magdalenienses arcaica o inferior, media con arpones, superior-final y aziliense, se debe a S. Corchón en su obra de conjunto sobre el espacio cantábrico (Corchón, 1986). La última actuación arqueológica en La Paloma tuvo lugar en la segunda mitad de los años setenta, acometida por un equipo de la Universidad de Salamanca bajo la dirección de F. Jordá Cerdá, pero no sabemos si en ella se llegó a excavar algún nuevo sector o, simplemente, se trató de la limpieza y reconocimiento de lo hecho en 1914-1915.

\section{LA ADDENDA MOBILIAR DE 2016}

Durante la visita de uno de nosotros (C. B.) en marzo de 2016 a La Paloma fue observada, en la confusión que la superficie del yacimiento ofrece a lo largo 
de los espacios sucesivos que en su momento fueron denominados "patio", "pórtico" e "interior", indicios de remociones y rebuscas con la consecuente presencia a la vista de algunos restos de utillaje lítico y, de forma más evidente, de bastantes huesos, algunos de los cuales- dos arranques de astas de ciervo con su pedículo y parte del hueso craneal, además de la rótula de un ciervo de tamaño considerable y algún fragmento de candil de la misma especie de ungulado, despojos sin contexto estricto-, que fueron después depositados en el Área de Paleontología de la Facultad de Geología de la Universidad de Oviedo.

Lo inesperado de ese reconocimiento visual fue el hallazgo de los dos fragmentos de asta con motivos ornamentales incisos que constituyen el objeto de este artículo. Emergían ambas piezas entremezcladas con cascajo y otros restos óseos en el breve espacio comprendido entre la pared que genéricamente discurre en dirección NW-SE y un bloque de caliza caído de la bóveda. El lugar conforma un pequeño entrante en el sector NE. del "Pórtico", en zona de penumbra, cerca y más alto que la Galería del ostra. Para su ubicación recurrimos ahora a uno de los planos; el relativo al estado de la cueva tras la campaña arqueológica de 1915 (Hoyos et al., 1980: fig. 6), dentro de la extensa zona de desarrollo del nivel 4 cuya matriz de gravas de caliza, indiciarias de un momento frío, muy riguroso, que culturalmente se correspondería con el magdaleniense superior (Fig, 1, a).

Obviamente, sería aventurado suponer que los materiales hallados procedan del aludido nivel, salvo que del mismo formara parte un delgado testigo sedimentario adherido a la pared, precisamente integrado de

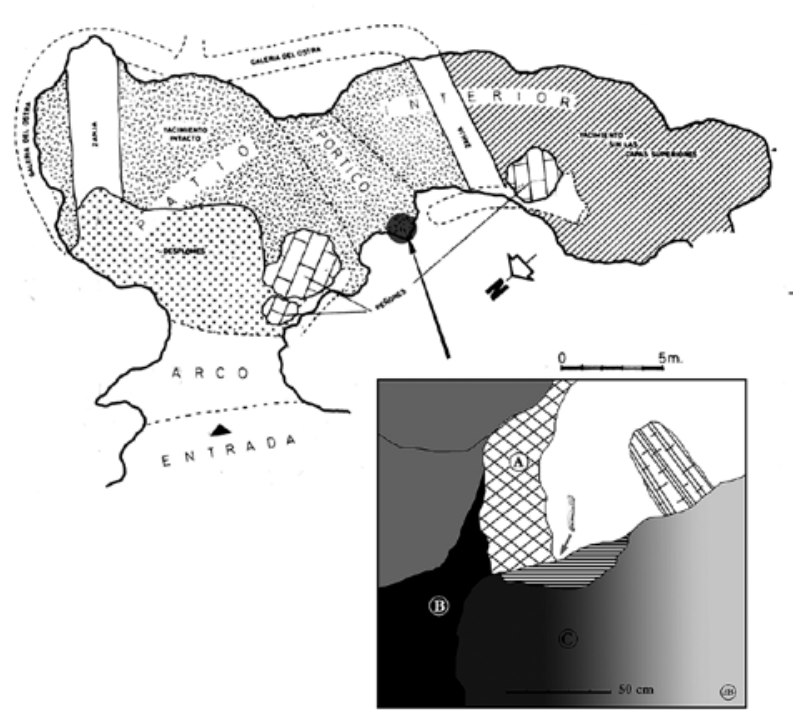

Fig. 1. Plano de las excavaciones de La Paloma en 1914-1915, según Hoyos et. al. 1980 con la indicación del lugar de hallazgo de las nuevas piezas mobiliares y croquis del mismo paraje en la actualidad con la anotación de la zona de los hallazgos de 2016 / Plan of the excavations at La Paloma in 1914-1915, according to Hoyos et al. 1980 with the indication of the place where the new mobiliary art objects were found and a sketch of the same place at present with the annotation of the zone of the 2016 finds. forma dominante por pequeños fragmentos angulosos de caliza entre los que no era escasa la presencia de huesos. De aquel relicto del relleno estratigráfico podrían proceder las piezas que nos ocupan, acaso desligadas del mismo y retenidas con otros restos orgánicos e inorgánicos en el hueco existente entre la pared y el bloque ya señalado. Tal como reflejamos en un croquis (Fig. 1,b) es acentuada la complejidad de la zona donde se confunden los vestigios de las excavaciones con las rebuscas, saqueos, hundimientos y los bloques de volúmenes variados desprendidos del techo. Al pie de una gran piedra caída hay indicios de rebuscas ligeras y de una probable selección de lo visto, procedimiento de segregación en el que entendemos no fue advertido el hecho singular de que dos de las piezas córneas allí localizadas incluyeran, recubiertas por la habitual película arcillosa, expresivas incisiones lineales.

\section{DESCRIPCIÓN GENÉRICA DE LAS PIEZAS}

La principal consiste en un fino tallo de asta de Cervus elaphus, -de $209 \mathrm{~mm}$. de longitud y $20-28 \mathrm{~mm}$. de diámetros de la sección subcircular-, probablemente de un horquillón, por tanto debida a un animal joven de quizá no más de dos años (Fig. 2). En su extremo distal se percibe la bifurcación fracturada de la rama a la altura del arranque de una liviana punta central. En el extremo opuesto el asta fue recortada tranversalmente y, en parte, en bisel, visible así el hueso esponjoso afectado, en un pequeño sector, por lo que parecen indicios de combustión. Es además apreciable el desgaste de la corteza, sobre la que se extiende una mancha alargada de color marrón y probable origen orgánico.

Muestra este sector proximal, en contraste con el resto del objeto, un grado tal de abrasión que sugiere una repetida acción manual sobre el mismo, siendo incluso verosímil que hubiera estado alguna vez encajada en otra pieza, ¿acaso interviniente en forma de mango? Hay, en efecto, algunas estrías transversales y otras microhuellas que delatan el acentuado contraste entre este sector manifiestamente erosionado y la frescura y magnífica conservación del resto del cuerno (Fig. 3, a).

Con la corteza activamente pulida, es evidente que para la preparación de una superficie susceptible de ser ornada se cumplió la eliminación de las rugosidades y canalículos característicos de la cuerna, particularidad original solo reconocible por la preservación de pequeñas manchas circulares como vestigios de las perladuras arrasadas.

La segunda pieza es el fragmento distal de una punta o candil de $80 \mathrm{~mm}$. de longitud, sometido a un intenso pulido que en algunas zonas le confiere aspecto marfileño. Una fractura longitudinal en la punta es sin duda antigua, apareciendo también pulidos sus bordes. Presenta algunas incisiones en el ápice que acaso provengan de los choques debidos a la actividad ordinaria del ciervo (Fig. 4). 


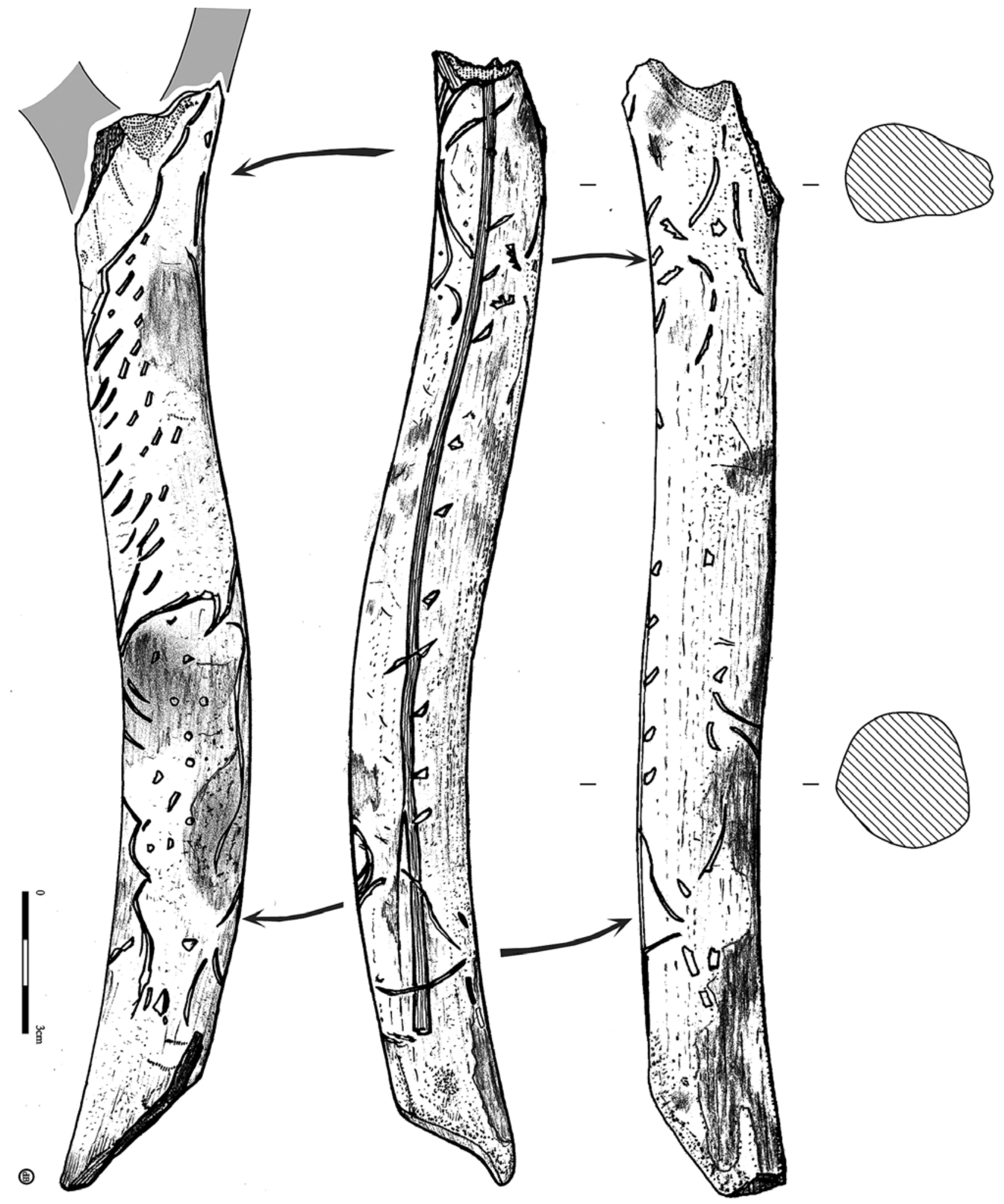

Fig. 2. Tres perspectivas de las superficies decoradas del asta de ciervo / Three views of the decorated surfaces of the red deer antler. 


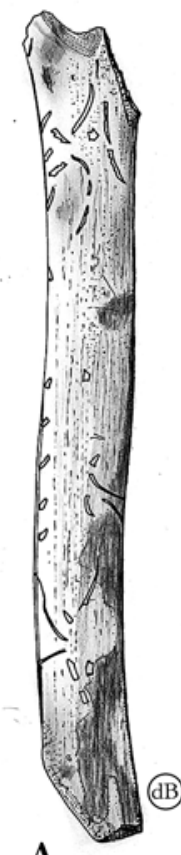

A
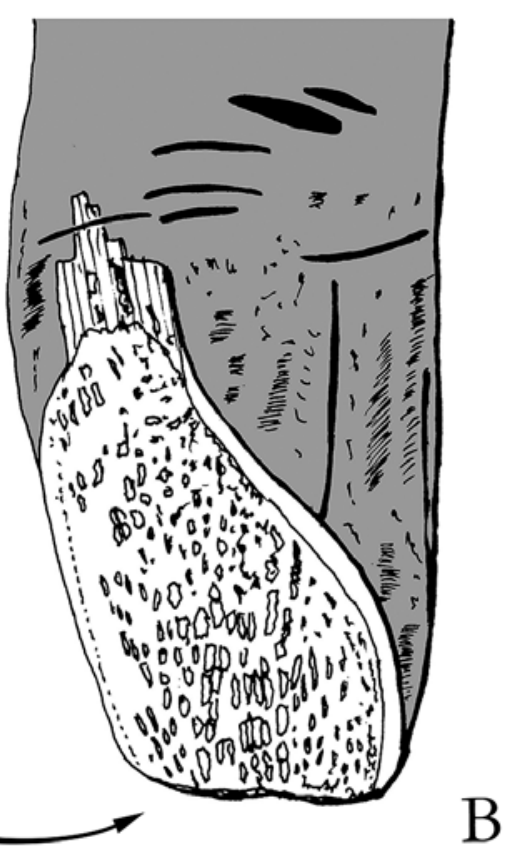

$\mathrm{B}$
(1)

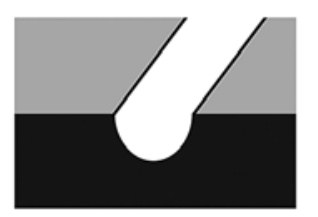

(2)

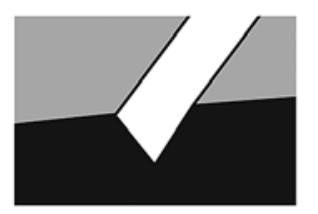

(3)

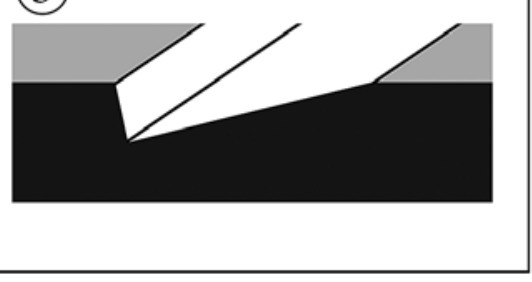

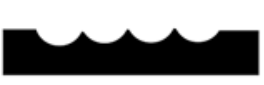

C

Fig. 3. A: abrasión, microfracturas e incisiones del extremo distal del asta decorada; B: disposición estriada del largo surco de grabado; C: Distintas formas del surco de grabado según la aplicación vertical u oblicua del buril, y la desigual eliminación de la materia materia córnea / A: abrasion, microfractures and incisions at the distal end of the decorated antler; B: striated form of the long engraved groove; C: different forms of the engraved groove according to the vertical or oblique angle of the burin, and the unequal removal of the horny matter.

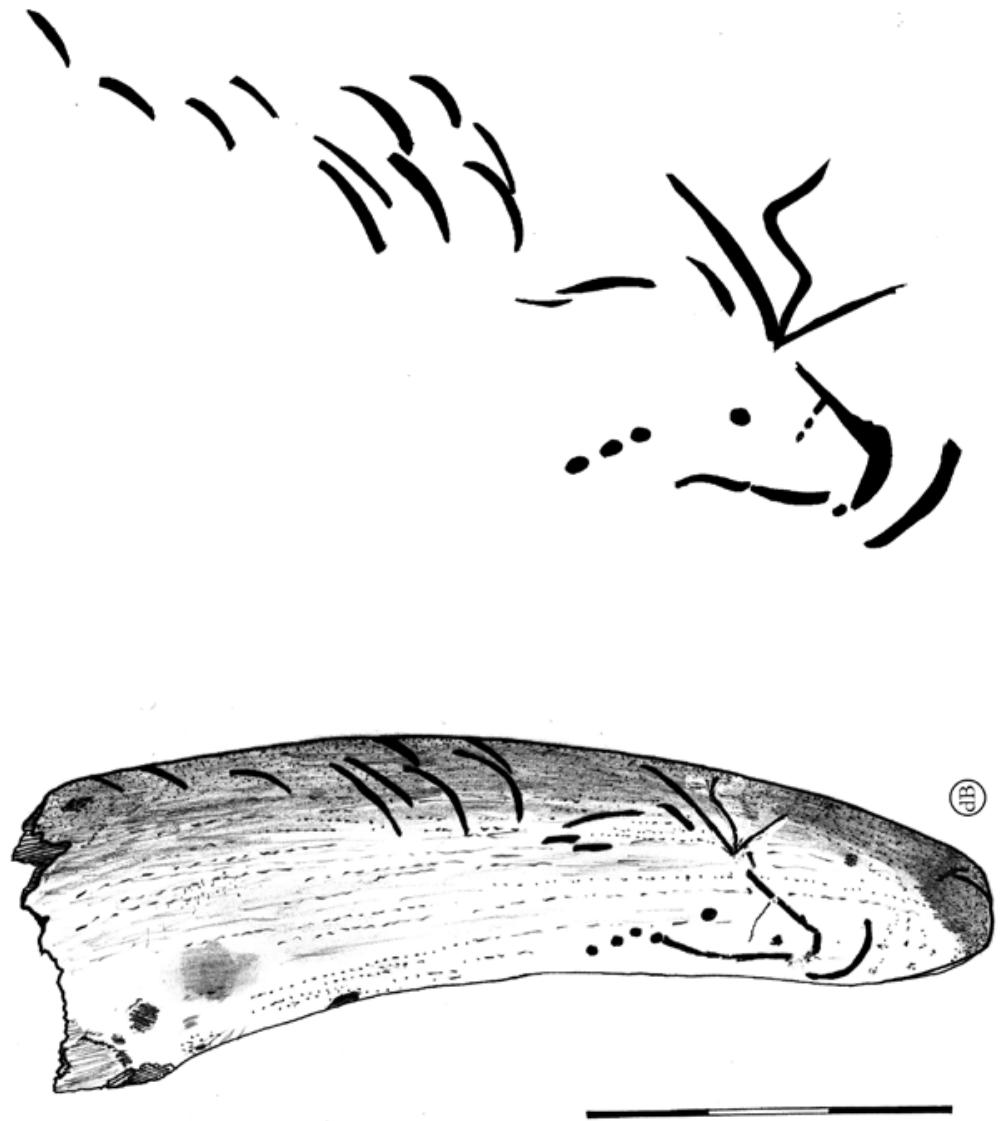

Fig. 4. El extremo del candil de ciervo y la representación grabada en el mismo / The end of the antler tine and the representation engraved on it. 


\section{LOS ASUNTOS GRABADOS}

1. El tallo de asta decorado. Tomando como eje de referencia un largo surco que recorre longitudinalmente la pieza, los elementos inscritos, de los que el aludido trazo axial forma parte, se distribuyen a ambos lados del mismo. De este modo, el campo figurativo se estructura en dos bandas en las que la ocupación de los motivos grabados es simétrica:

a. La superficie está ocupada casi en su totalidad por dos figuras de animales que miran hacia los respectivos extremos (Fig. 5).

a.1: la figura más completa de todas representa un cérvido de cornamenta bien precisa que mira a la izquierda, con el cuello extendido de manera que la cabeza queda levantada, resuelto el ojo por una simple incisión triangular. En el tránsito al pecho se dibuja la angulosidad propia de una papada, avanzando el trazo quebrado hasta la unión con la pata delantera, esbozada por una simple línea. El volumen corporal queda resuelto con una larga línea iniciada en la breve curva alusiva a una cruz jibosa, registrada la línea dorsal hasta la inflexión de la que parte la cola aguda, de la que, a su vez, nace la pata trasera resumida en dos trazos. Completan el motivo una serie de incisiones oblicuas, dispuestas en paralelo y de tamaño desigual, algunas de hasta $8 \mathrm{~mm}$. de largo, siendo otras apenas un trazo mínimo.

a.2: De espaldas a la anterior, mirando por ello a la derecha, se inscribe otra representación de cérvido cuyos cuernos siguen genéricamente en la orientación de sus candiles la pauta de a.1. La cabeza de la que parten las astas, de morro ancho sin que quede cerrado por la línea de grabado, sugiere una boca abierta en la que un par de trazos breves parecen expresar la lengua emergente. Una corta línea dorsal anota la cruz sin alcanzar el extremo trasero, mientras que del tramo inferior del cuerpo la sucesión de dos trazos curvados dibuja la papada y el pecho a los que sigue la anotación sumaria, con dos líneas, de la pata delantera. Una serie de puntos, ocho o nueve, aparecen en el área correspondiente al cuerpo y, bajo ellos, tres trazos curvados, similares a los registrados en a.1. Consiste, en síntesis, en la representación parcial de una bestia de la que falta su tercio posterior.

b. Son también dos en esta otra cara los temas faunísticos; sin embargo, es notable el cambio de registro gráfico: protomos, no cuerpos completos o, al menos más detallados, figuras que al igual que en a se dan la espalda (Fig. 6).

b.1: Mirando a la derecha se sustancia el protomo de otro cérvido somero. Una línea continua dibuja la sucesión frente-nariz; las restantes, en dos trazos interrumpidos, delinean el maxilar y el tránsito del cuello al pecho, una; la línea de la nuca e inicio del lomo, la otra. En el esquemático dibujo, de proyección triangular de la cabeza, una incisión subcircular o estrellada conforma el ojo. En el lugar pertinente, dos formas con perfil de sierra anotan las pequeñas astas del animal.

b.2 : En el mismo sector del asta que en a.2 acoge al cérvido incompleto, lo inscrito en b es una figura sumaria en la que pocos trazos describen dos cuernos, una escueta oreja, una línea discontinua para precisar el plano fronto-nasal, el ojo de nuevo de forma triangular, una línea sugerente de la nuca y cuello, y cuatro trazos más

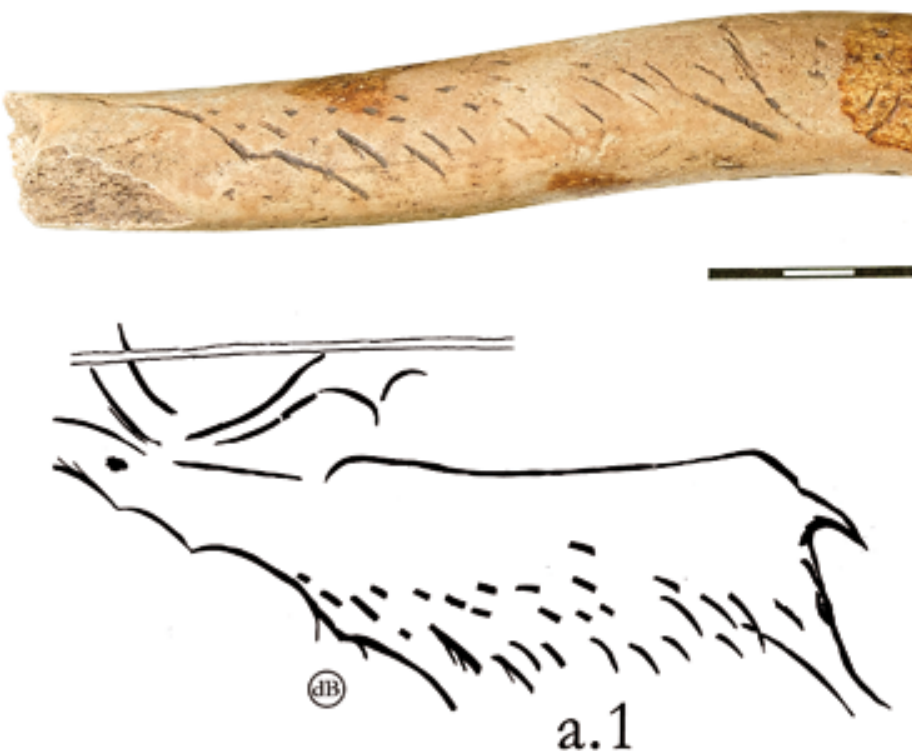

Fig. 5. Motivos faunísticos (renos) grabados en la cara a del asta / Animal motifs (reindeers) engraved on Face a of the antler. 


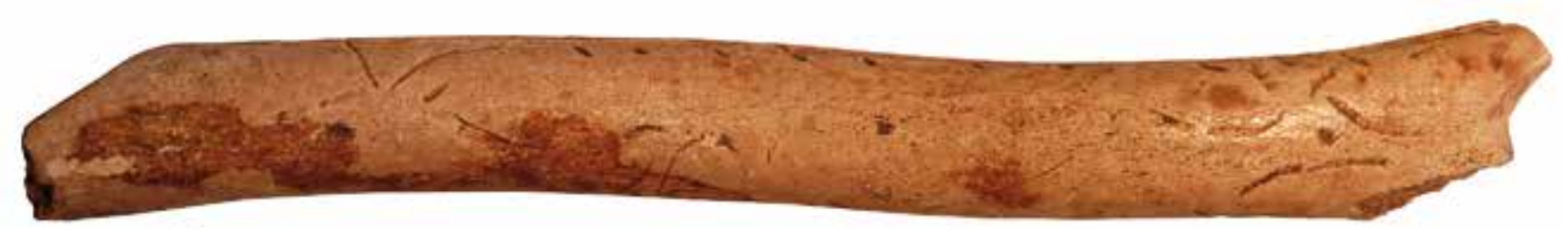

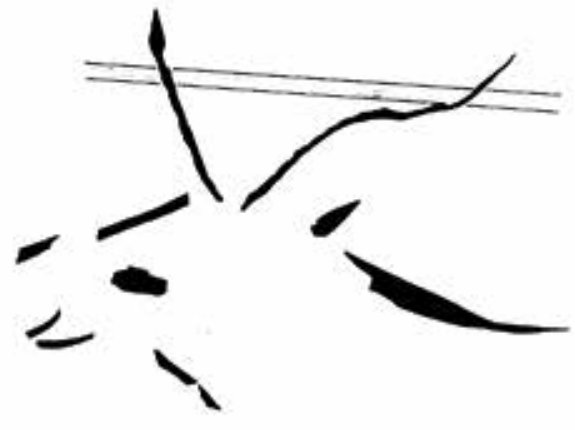

b. 2

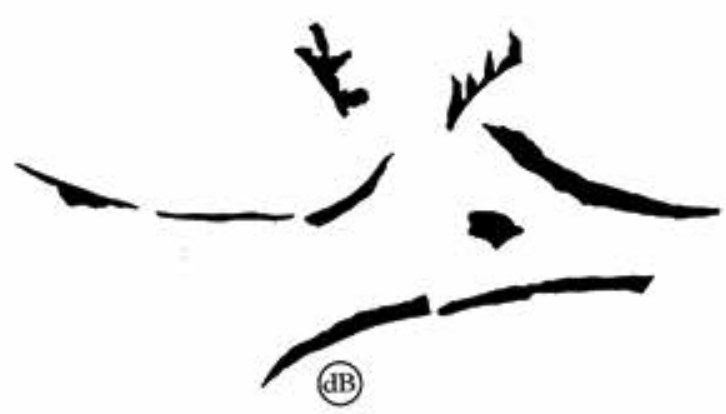

b. 1

Fig. 6. Protomos de animales (cabra y reno hembra) grabados en la cara $b$ del asta / Animal heads (goat and female reindeer) engraved on Face b of the antler.

alusivos al sector inferior de la garganta y a dos rayas indicativas de una barba. Con tales argumentos no parece que se pueda defender otra identificación que la de un cáprido macho.

Entre b.1 y b.2 media un amplio campo vacío en el que sólo aparecen, al margen de la intrusa pata de a.2 que invade brevemente la cara b, un par de rayas cortas de declarada forma triangular.

Por último, y como elementos no figurativos, en cualquier caso temas lineales no asimilables a elemento orgánico reconocible, está el largo surco de $170 \mathrm{~mm}$. de recorrido, que sin fin establecido a causa de la rotura del extremo distal, sí acaba con un frente recto bien definido en el proximal.

Sobre su lado derecho, orientada la pieza verticalmente con el extremo proximal abajo, se registran diez trazos cortos, oblicuos sobre el borde acanalado, ejecutados son posterioridad a aquél. De la serie de vírgulas solo una, resuelta con dos trazos alineados, llega a seccionar con claridad el surco, circunstancia que tal vez responda a una bien determinada intención.

2. El extremo de candil. En este caso, orientada hacia su ápice, la anotación incisa dibuja la cabeza de un cérvido de cuerna poco desarrollada, con la boca sugerida por la discontinuidad de la línea de grabado y una escueta referencia al dorso del animal que entendemos señalada por una decena de trazos ligeramente curvados. Poco se podría objetar a la propuesta de la alusión a un pelaje rudo y erizado lo que, como comentaremos, podría reflejar una bien determinada condición de la bestia.

\section{LAS TÉCNICAS DE GRABADO Y SU DIACRO- NÍA RELATIVA}

El surco axial con una anchura de $2 \mathrm{~mm}$. se compone de la suma de cuatro largas y paralelas líneas incisas abiertas con un buril agudo. En su largo recorrido se observan varios deslizamientos del instrumento de labra, en especial en el muy nítido desvío de la línea a la altura de los cuernos de a.2 y b.2. Es, además, digno de consideración el hecho de que el surco aparezca más erosionado en su inicio sobre el sector proximal, consecuencia lógica de la llamativa abrasión general que ofrece aquella parte del cuerno (Fig. 3: B y C).

Por su parte, los trazos cortos convergentes con el gran surco responden a una diferente forma de ejecución; más clara la producida por un corte en bisel, o de sección en $\mathrm{V}$ asimétrica abierta; en consecuencia, determinando un lado del ángulo diedro resultante mayor que el otro.

En a. 1 el surco que describe la parte superior de la figura, seguro y limpio, sin titubeos en su ejecución, es en $U$, mientras que en la inscripción del tramo maxilar-papada-pecho-pata delantera el trazo labra una $V$ asimétrica. Allí, un primer tajo de buril, el más inclinado, vino a actuar como tope de una segunda corta de menor inclinación, procedimiento pertinente para extraer más materia córnea, acentuando la visibilidad del trazo de grabado. Con tal procedimiento se aprecian mejor las discontinuidades en el esfuerzo de incisión, con derrapes y correcciones más evidentes en la cola e inicio de la pata trasera. La ejecución de lo que constituye el ojo del animal queda resuelta por dos cortas incisiones formando un ángulo.

En cuanto a los segmentos cortos que cubren parte del interior de la figura llama la atención en los menos largos su forma de aguja o espina, marcado su arranque 
con un frente regular donde el buril allí hundido con resolución empieza su andadura hasta diluirse parte de esa regularidad en el extremo, disminuida la presión sobre la corteza.

Con toda claridad se manifiesta el surco en V asimétrica abierta determinante de la línea fronto-nasal de la figura a.2, incidiendo el buril oblicuamente con respecto a la superficie del asta, figura en la que el trazo relativo a la mandíbula presenta varios deslizamientos del útil de trabajo que hacen que la insistencia en la definición del dibujo resulte evidente. Para la anotación del ojo el buril incidió radialmente para el excavado de una forma subelíptica.

Pese a lo que cabría suponer dada la disposición de los motivos inscritos: que el primer trazado sobre la corteza de la cuerna previamente pulida sería el nítido surco longitudinal, actuando así como eje orientador de todos los demás motivos, el hecho seguro es que antes había sido grabada la figura del cérvido completo, una de cuyas puntas (I) fue cortada por el posterior trazo lineal de fondo estriado (II) (Fig. 7). Sí, en cambio, fue posterior la ejecución del protomo del animal b.2 cuyos cuernos (IIla) se despliegan seccionando el surco. Son asimismo posteriores al gran trazo lineal las vírgulas incisas (IIlb), oblicuas, que en todos los casos en que contactan con aquél lo hacen cortándolo; una relación justa si entendemos la dependencia que los trazos cortos deberían de tener con respecto al gran surco. Esa relación es aún más patente con el trazo corto, grabado en dos partes, cuya ejecución posterior es indiscutible.
La falta de cualquier intersección o contacto entre sí de las restantes figuras no tolera mayores especulaciones sobre la secuencia de la inscripción de los motivos. Se podría suponer que el cérvido a.1, completo, sería anterior al a.2 representado parcialmente, pero tal conjetura olvidaría el hecho esencial de que el artista paleolítico pudo actuar con libertad permitiéndole, también en este caso, dibujar una bestia completa, acomodada al espacio figurativo disponible. La representación parcial fue por tanto una elección,- fueran cuales fueren las razones-, sin que pudiera influir, por irreal, un impositivo límite espacial.

\section{EL CONTENIDO ICONOGRÁFICO}

\subsection{Los elementos lineales}

Recurriendo a la precisión de los términos recuperados recientemente por I. Barandiaran, el nuevo tallo de asta decorada de La Paloma reúne elementos interespecíficos: la coincidencia de figuras animales de distintos géneros, heterogeneidad a la que se suman además las representaciones de signos (Barandiaran, 2003: 13).

De estas últimas el repertorio no puede ser más escueto, destacando el largo surco de final desconocido a causa de la fractura del extremo distal de la pieza. Por el contrario, su inicio, con dibujo cuadrangular, se precisa de manera cuidada en el extremo distal. Una primera impresión es que el surco dibuja un trazado curvilíneo, aunque tratándose, en realidad, de la acomodación de una desea-

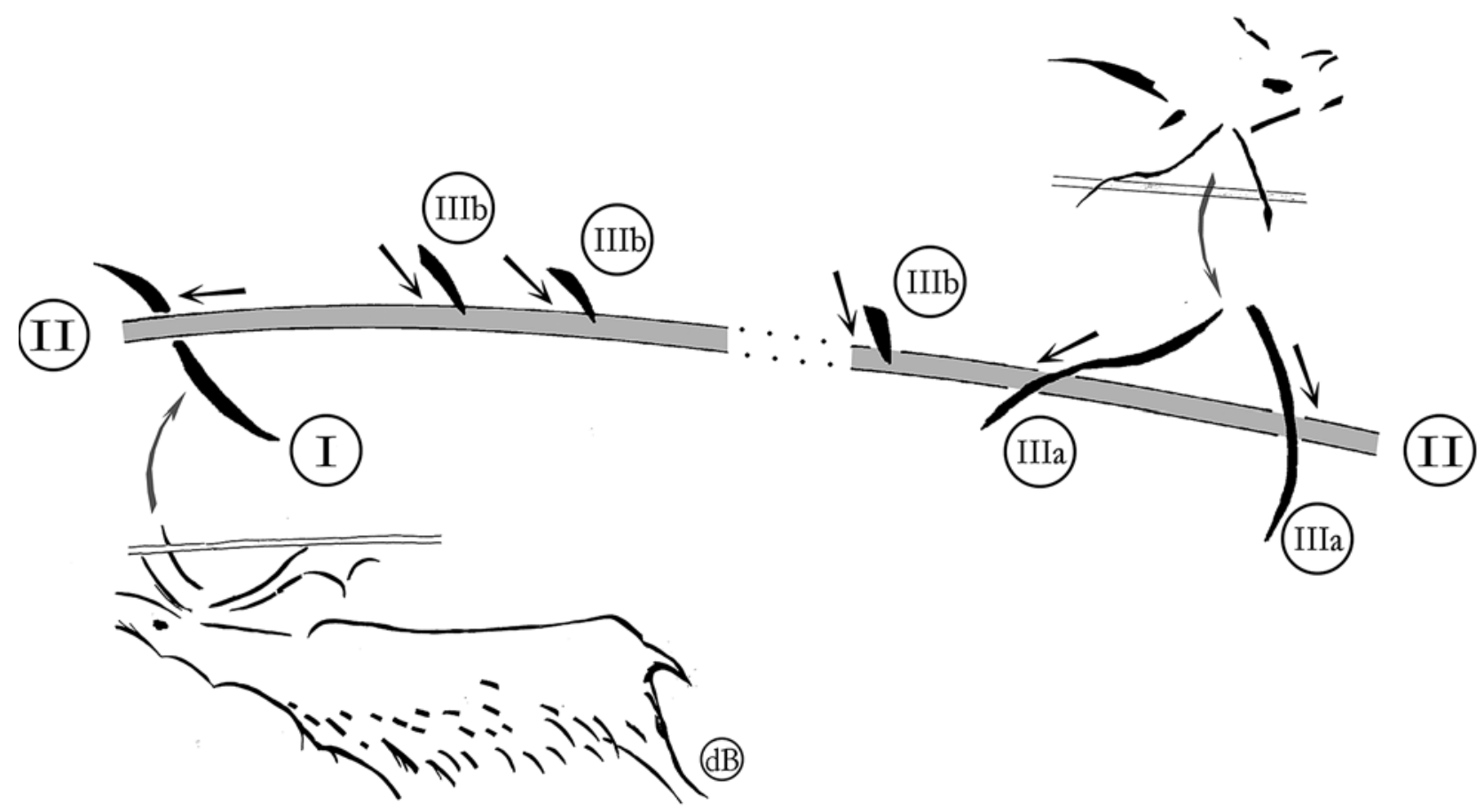

Fig. 7. Intersecciones de las líneas de grabado y su orden de ejecución / Intersections of the engraved lines and their order of execution. 
da línea recta a la discreta, pero influyente, curvatura del asta. Quizá fuera ese delineado el seguido previamente por una de las estrías o canalillos longitudinales característicos de la cornamenta de ciervo, línea de referencia que muy desvaída, como una vaga mancha, habría sobrevivido al pulimento aplicado al cortex. Sin embargo, su límite proximal es tan acentuado que hubo de responder a un expreso deseo de anotación de su inicio o final.

Con el ancho y largo surco se relacionan una serie de virgulillas o trazos cortos, de entre $5 / 6$ y $2 / 3 \mathrm{~mm}$. de longitud, siempre convergentes con el canal grabado, en posición oblicua con respecto al mismo y dispuestas todas ellas en el mismo lado o, si se quiere buscar alguna relación topográfica, en el sector del tallo donde se inscriben dos protomos de animales de distinta especie, la faz, pues, contraria a la más historiada donde fueron inscritos los motivos capitales del asta: dos magníficos cérvidos.

Constituye la excepción a la pauta de los trazos cortos aquel que cruza claramente el largo surco, grabado tanto a un lado como al otro del mismo. Esa distinción quizá tenga su origen en el ritmo que entendemos siguen los parcos trazos. Es probable que las diez vírgulas respondan a una pauta ternaria: tres veces grupos de tres, separados por un cierto intervalo o, en un caso, por el trazo diferente (Fig. 8). Serían, en consecuencia, nueve trazos segregables de otro décimo, formalmente bien diferenciado de los demás, que bien pudiera señalar la cesura entre dos grupos de tres.

No es nuestra intención esbozar cualquier intento esclarecedor del supuesto ritmo ternario señalado,- el tres como número universalmente fundamental-, pero sí recordar que el motivo de la acanaladura asociada a cortos trazos transversales se documentaba ya en La Paloma en una probable azagaya de sección cuadrangular, registrada en las excavaciones de los niveles del magdaleniense medio (Barandiaran, 1971: 259, fig. $4^{\mathrm{a}}$ y 1973: pl. 20; Corchón 1986: 351), y que en algunos casos realmente notables, tómese como guía esencial la lezna de Bolinkoba, se reitera la anotación de marcas cortas con lo que parece un intención secuencial de registros binarios y ternarios (Barandiaran, 1966: 53 y 1973: lám. 19-7; Corchón 1986: 341 y fig. 99). Sea cual fuere su objetivo, la del trazo longilíneo cruzado oblicuamente por trazos cortos es una asociación bien documentada en estratos del magdaleniense superior y final de la costa cantábrica tal como puede observarse en las cavernas de Cueto de la Mina, El Pendo, El Valle, Lumentxa o Santimamiñe.

\subsection{Las figuras de animales}

Es poco probable que tanto la figura a. 1 como la a.2 representen a una especie de cérvido distinta a Rangifer tarandus L. En a.1 predomina el aspecto general musculado y magro del reno, además del morro ancho y pesado, identificación a la que apunta también la disposición característica de la cornamenta con sus paletas anteriores, y la extensión hacia atrás del can-

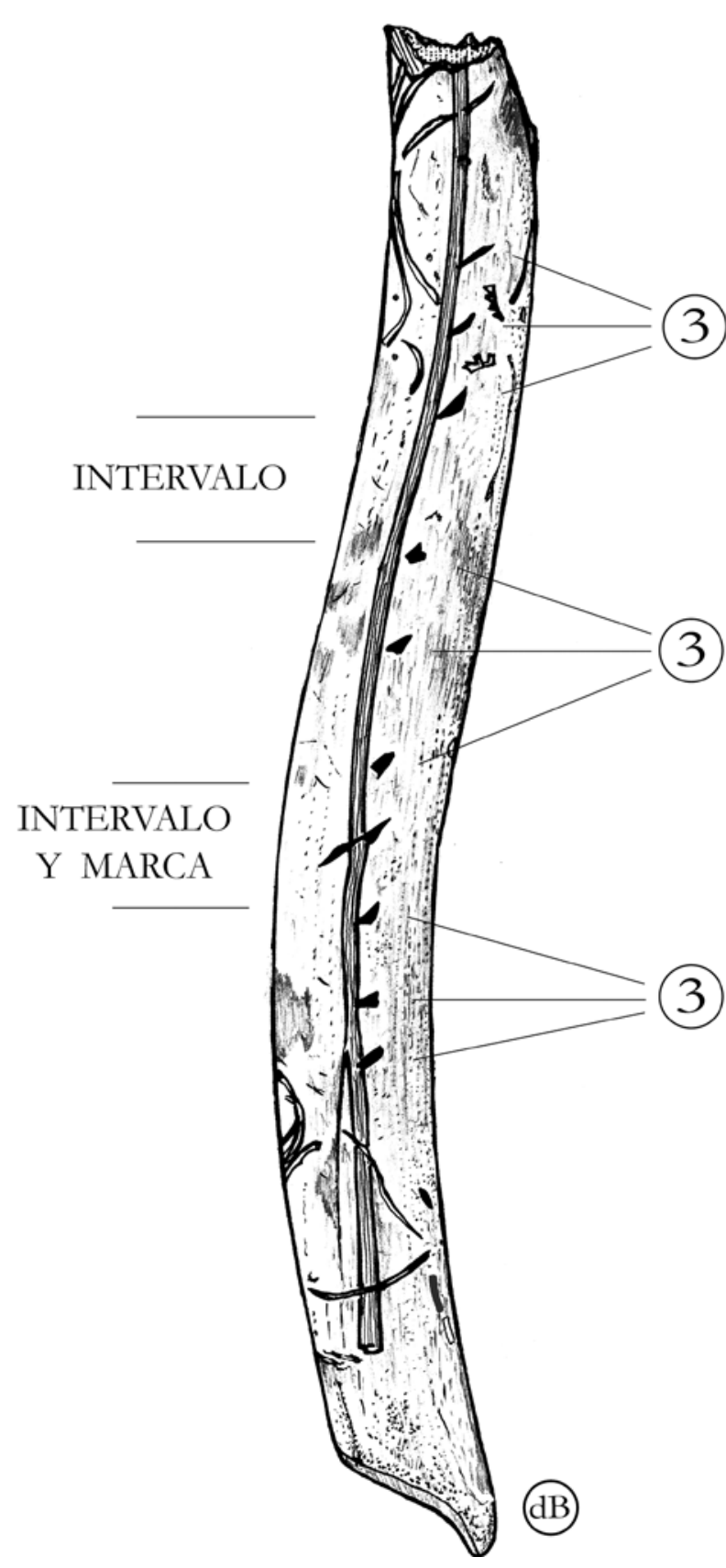

Fig. 8. El largo surco en el asta y los trazos cortos asociados al mismo / The long groove on the antler and the short lines associated with it.

dil que nace del tallo o rama principal. A este último respecto conviene recordar que el recurso a la simplificación gráfica de las ramificadas cuernas de reno es bastante habitual en el arte paleolítico aún cuando su intención sea realista (Barandiaran, 1969).

No son menos expresivas la anotación explícita de la cruz en el arranque de la línea dorsal, el detalle de la papada y la angulosidad en la unión del pecho con la pata delantera, además de la característica cola, alta, corta y de extremo agudo. No ofrecen menor interés la 
casi treintena de trazos que en posiciones oblicuas y paralelas cubren el tercio inferior del cuerpo del animal en lo que cabría identificar como capa característica. Puede ser anotada como curiosidad estilística de este reno de La Paloma su formulación gráfica tan cercana a la de una bestia de la misma especie grabada en un baston de asta del abrigo alemán de Peterfelds, en Bade-Würtemberg (según Peters 1930, figura incorporada en Barandiaran 2003: Fig. 4, 9).

Tal vez sea aventurada la interpretación de un pelaje tan resaltado gráficamente como representativo de los pelos blancos y largos que nacen en el reno en su época de celo, colgando con su punta triangular (Soubeyran, 1993; Azema 2009), pero no es menos sugerente a tal respecto el que además se alarguen los hombros y el escote del cuello, disposición sintomática de un estado de excitación. En todo caso es frecuente que la forma de la capa se utilice como argumento de peso en la definición sexual del reno (Bouchud, 1966: 15).

Acaso se pueda reconocer como indiciaria de una similar tensión la morfología del animal de la figura a.2, que también interpretamos como un reno de precisa papada, cabeza gruesa, capa de largos pelos y asta de candiles nuevamente crecidos hacía atrás. No es un detalle despreciable la anotación de la boca abierta de la que emerge un corto trazo, siendo su postura con la cabeza y el cuello tendidos horizontalmente (low-strench posture), la forma de aproximación del macho a la hembra, sacando la lengua alternativamente, mostrando su pelaje blanco y retirando hacia atrás las cuernas para minimizar su agresiva aparatosidad (Fig. 9: $a$ y b).

Es todavía de otro cérvido el sumario protomo consignado como b.2. que con sus cortos cuernos en espina bien pudiera representar una hembra al final del verano o principios del otoño, de acuerdo con la morfología cambiante de las astas a lo largo del ciclo de reproducción (Crémadès y Bonissent 1993, en Azema 2009: 133) (Fig. 9: c).

Por último, en b.1 nos hallamos ante la cabeza y cuello de lo que entendemos como un cáprido, la cabra montesa, que por la doble curvatura del asta cabría reconocer como macho de Capra pyrenaica. Clasificado como el animal de montaña por excelencia, lo es en realidad más de las paredes rocosas y abruptas que de las grandes altitudes. Maniobrando con escasa habilidad en las zonas cubiertas de nieve, circunstancia en la que resulta vulnerable, suele descender bastante abajo en los valles durante el otoño.

Tampoco cabría descartar en este caso el que la posición del cáprido, extendida la cabeza, con el ojo y la oreja en planos próximos, y algo hacia atrás los cuernos, responda de nuevo a la referida como "parada en la incitación al acoplamiento" (Azema, 2009: 109, fig. 80).

En fin, la verosímil actitud que inducimos de los dos renos machos representados no es incongruente con el hecho de que el tercer ejemplar de Rangifer, una hem-
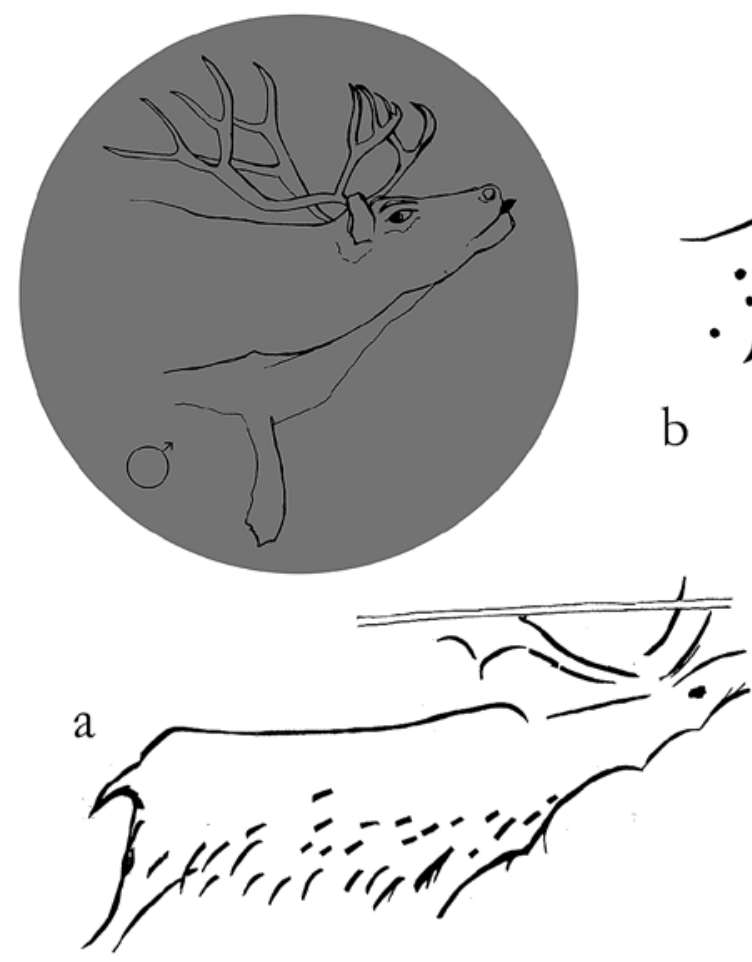
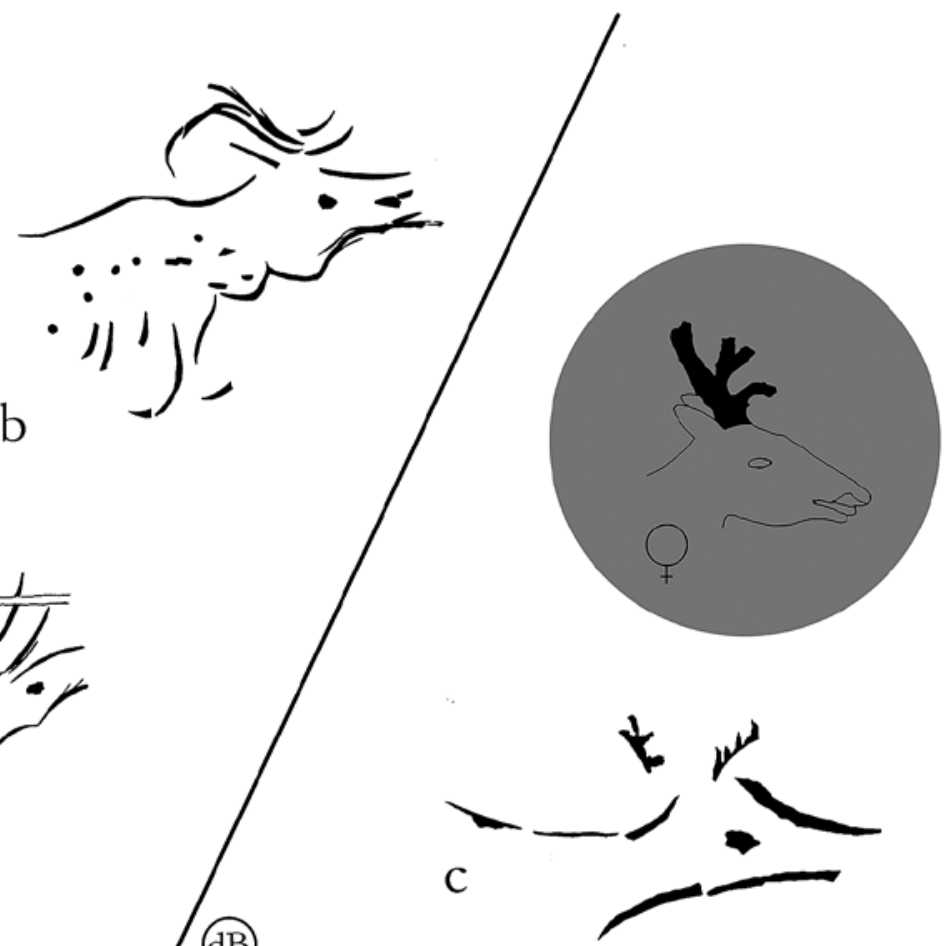

Fig. 9. Renos macho de La Paloma (a y b) y actitud de un reno en celo; hembra de reno de La Paloma (c) y episodio en el desarrollo de sus astas / Male reindeer at La Paloma ( $a$ and b) and attitude of a rutting reindeer; female reindeer at La Paloma (c) and episode in the growth of their antlers. 
bra, presente la cornamenta propia de la época en que tiene lugar su breve ciclo sexual, limitado a tres o cuatro semanas, apareciendo los primeros síntomas de celo a finales de agosto, aunque tal estado pueda prolongarse hasta octubre o incluso noviembre. Bajo este enfoque no es fácil obviar la impresión de que lo figurado en el asta pudiera guardar alguna relación con los mecanismos de reproducción de una especie animal de alto valor cinegético; que la expresión artística viene a engranarse a través de un discurso probablemente muy complejo e irreconstruible en la realidad vital, en la comprensión de la naturaleza y de las opciones de supervivencia en la misma de las experimentadas sociedades de cazadores de los episodios terminales del paleolítico superior.

En cuanto al animal figurado en la segunda pieza, el extremo de candil, bien pudiera tratarse de un individuo joven de Cervus elaphus si se acepta como apoyo diagnóstico el dibujo tan escueto de la cornamenta. Hay, desde luego, un detalle que el autor del grabado se empeñó en resaltar: lo que interpretamos como el rudo pelaje que suelen presentar los machos en la parte anterior de su cuerpo. Son precisamente tales cerdas largas y gruesas las que el ciervo eriza durante la época de celo (Mardyla 1981, según Azema 2009: 116).

No dejan de ser estas ligeras consideraciones interpretativas formas de aproximación en las que I. Barandiaran, con su habitual despiece analítico hasta el extremo, descubre el bucle argumental trazado por la mezcla de razonamientos deductivos (como el pelaje, los supuestos gestos de celo, etc.) e inductivos (como la apariencia grupal de un tema entendida como alusiva a una determinada estación, etc.); en efecto, mecanismos interpretativos a los que se suele recurrir enfrentados a las numerosas variantes del argumento macho/ hembra (Barandiaran, 2003).

\section{ALGUNA CONSIDERACIÓN SOBRE LOS RE- NOS EN EL CANTÁBRICO Y EN EL ARTE MOBI- LIAR REGIONAL}

Los hallazgos paleontológicos recientes en la cueva de La Rexidora (Ribadesella, Asturias) revelan en el intervalo C14 de 44.500 a 37.600 cal. BP, correspondiendo pues con la fase isotópica MIS 3, la realidad de ciclos fríos determinantes de un ambiente estépico en el que habrían vivido en este enclave central de la región cantábrica poblaciones animales tan características de condiciones térmicamente muy rigurosas como el rinoceronte lanudo (Coelodonta antiquitatis), además de Bison priscus y la especie que aquí nos interesa: Rangifer tarandus (Álvarez-Lao et al., 2015).

Muchos milenios después, ya en la fase climática H1 (16.600- 14.600 años BP), episodio simultáneo de la continuidad de los estadios magdaleniense medio y superior, se cuentan al menos 13 localizaciones con testimonios materiales de Rangifer en el marco espacial cantábrico. Hay aún indicios más recientes en la fase temprana del Dryas (YD), postrera oscilación fría datable hacia 12.700 - 11.300 años atrás, coincidiendo con el estertor magdaleniense y la formulación del ciclo cultural aziliense. Aportan pruebas de esta circunstancia postrera los registros faunísticos de la Cueva de la Riera, en Llanes, donde fueron datados los restos de reno en 12.500 cal. BP. (Altuna, 1986) y lo documentado en un momento aún más tardío en la cueva vizcaína de Santa Catalina, en fechas de 14.400- 10.300 cal. BP., asociados los vestigios de aquel cérvido a una industria aziliense (Castaños, 2014). Hablaría pues la fauna fósil de un panorama zoológico en sectores de la banda marítima septentrional de la península no demasiado alejado al constatado en el contiguo territorio francés donde, en los depósitos arqueológicos de Duruthy y Dufaure, se hallaron renos en niveles de filiación aziliense (Delpech, 1983 y Altuna, 1996)

Estos breves apuntes: presencia, que no abundancia, de una especie tan característica de los compases terminales del Würm, dan congruencia a lo observado en el arte mobiliar del paleolítico cantábrico, fenómeno plástico en el que los renos vienen a constituir del 2 al 3\% en la iconografía faunística, siendo creaciones gráficas ubicadas mayoritariamente en el proceso magdaleniense medio- magdaleniense avanzado. Son de destacar como testimonios representativos al respecto las figuras de reno inscritas en las placas de arenisca de Urtiaga y Aitzbitarte IV, más las dos probables del colgante o bramadera de El Pendo, el par de cabezas ya aludidas del hueso de águila de La Paloma (¿o de La Cuevona?), el grabado en un omóplato de la Viña, y la representación parcial en una placa de Tito Bustillo (Barandiaran, 1994: 58), repertorio al que se suman las tres vigorosas representaciones plasmadas en dos plaquitas de arenisca yacentes en los niveles del magdaleniense medio de Las Caldas (Corchón, 1992).

Es bastante más incierta, sin embargo, la identificación de renos en el magdaleniense inferior, si acaso presente una de sus representaciones en uno de los omoplatos de grabado estriado de la caverna de El Castillo, cérvido en el que los candiles que nacen en el tallo se desarrollan hacia atrás, al contrario de lo que sucede con las astas de elaphus (Corchón, 1986: 204 y 237). Desde luego, tal detalle no carece de notoriedad, salvo que el autor del grabado se tomara la libertad de girar el cuerno, viéndolo de desde detrás de la cabeza, desplazamiento que justificaría la inhabitual posición de las puntas.

Quizá las condiciones climáticas de la fase primera del magdaleniense medio en el occidente de la región cantábrica, el riguroso episodio Dryas antiguo superior, hayan sido ajenas a esta concreción iconográfica; al menos es esa contemporaneidad la que reflejarían los hechos observados tanto en el gran refugio de La Viña como en la gruta de Las Caldas, ambos yacimientos del curso medio de río Nalón, del mismo modo que en ese mismo ciclo cultural se hacen patentes las conexiones, al menos la cercanía en objetos mobiliares y 
ornatos tratados, con el espacio pirenaico, sintonía de la que recientemente aportan sustanciales noticias los materiales de la cueva de Las Caldas, cercana a la ciudad de Oviedo (Corchón et al., 2015).

Son en cualquier caso coherentes estas consideraciones con el marco general determinado por el registro de los restos óseos de reno que ya hace tiempo fue señalado en 25 niveles cavernarios cantábricos: cuatro del magdaleniense inferior, dos del medio, catorce del superior y otros cinco en episodios magdalenienses no precisados; testimonios paleontológicos que ya en Asturias se sustanciaban en un resto en Tito Bustillo, siete en La Riera, y uno en Cueto de la Mina, insertos en estratos, en los tres yacimientos, del magdaleniense superior. Del mismo modo, en ese tiempo avanzado del magdaleniense adquiere la estampa del reno su más nítida expresión en los cuatro individuos pintados en bicromía en el conjunto $X$ y acaso otros seis en los conjuntos $X$ y VIII del complejo cavernario de Tito Bustillo (Balbín, 1989); elección figurativa acorde con la aludida placa de la misma gruta (Moure, 1982) en la que se reúnen reno y caballo, la misma dualidad animal fijada pictóricamente en las paredes de la caverna ribereña del Sella.

El necesario rigor ambiental que provocara el desplazamiento de los renos a lo largo de la región cantábrica no es contradictorio con la realidad del elaphus como cérvido dominante a lo largo del Würm en la extensa región costera, dominio del que se induciría un cierto atemperamiento térmico, siendo a menudo considerada como especie adaptada a un paisaje de abundantes bosques frondosos. Desde luego, en tal simplificación argumental se olvida que el ciervo llega a aclimatarse al bosque de coníferas y que, tal como ocurre en Escocia, puede incluso vivir de forma permanente en territorios colonizados por extensos brezales en los que apenas llega a medrar la vegetación arbórea (Altuna, 1996).

\section{LA UBICACIÓN CRONOCULTURAL DE LOS NUEVOS TESTIMONIOS DE ARTE MOBILIAR}

Tanto la solidez del tallo de ciervo como sus dimensiones toleraban sin riesgos la toma de una muestra para su datación radiocarbónica AMS. La pequeña fracción de material fue extraída de la cara interna de la corteza, alcanzada aquella zona recóndita tras la apertura en el extremo proximal del objeto de un pequeño conducto a través del hueso esponjoso ${ }^{1}$. La fecha resultante, medida en el Ángstrom Laboratory de la Uppsala Universitet, es $12899 \pm 44$ BP (Ua-53996; $\sigma^{13}$ C\%。 VPDB: -20.4) cuyo intervalo temporal, con un $95.4 \%$ de probabilidad cal. BC., se ubicaría en 13670 - 13260 (Reimer et al., 2013. Ox Cal. V3. 10; Bronk Ramsey 2005).
La fecha BP es plenamente compatible con varias de las datas AMS de piezas mobiliares de La Paloma obtenidas hace más de cinco lustros por I. Barandiaran, en particular con las correspondientes a sendos fragmentos de azagaya datados en $12860 \pm 130 \mathrm{BP}$ $(10.910 \pm 130 \mathrm{BC})$ y $12750 \pm 130 \mathrm{BP}(10.800 \pm 130 \mathrm{BC})$ (Barandiaran, 1988: 69; fig 3-1 y 3-2), si bien conviene subrayar que en ambas resultó por entonces excesivo el margen de desviación estadística con la derivada incertidumbre en su conversión en años solares. Pero no es solo la relativa cercanía temporal BP lo que aporta coherencia a la ubicación cronológica de una pieza que entendemos extraordinaria; lo es también el que las aludidas azagayas muestren motivos animalísticos grabados: cabeza y cuello de ciervo, una; un cuadrúpedo de larga cola, acaso un caballo, además de una cabeza sumaria, tal vez de cabra, la otra. Tanto la técnica de ejecución como la forma en que se disponen las figuras sobre la superficie ornada y ciertas afinidades estilísticas en la representación del cérvido permiten reconocer un cierto grado de proximidad en su resolución gráfica, destacando al respecto la angulosidad en las líneas de trazado del reno casi completo en el astil de ciervo que ahora damos a conocer.

La conjugación de la doble perspectiva radiocronológica y estilística no parece otros vestigios mobiliares aludidos en la misma gruta, entenderíamos que la presente addenda artística hubo de ser obra de los grupos generadores del ciclo magdaleniense superior en la cuenca media-baja del río Nalón. A tenor de lo señalado más arriba, a propósito de la estancia bien documentada de los renos en el segmento central de la región cantábrica durante aquellos milenios, sería evidente el conocimiento directo de los mismos por las poblaciones magdalenienses locales, observadoras de su morfología, hábitos y gestos para, al cabo, bajo un impulso creativo probablemente ritualizado, constituirse en temas figurativos resueltos con una extraordinaria concisión y elegancia formales.

\section{BIBLIOGRAFIA}

Altuna, J., 1986. The Mammalian faunas from the prehistoric site of La Riera. In: L. G. Staruss \& G. Clark (Eds.), La Riera Cave Stone Age Hunter-Gatherer adaptations in Northern Spain, 237-274, 412-479, 481-497, Tempe, Arizona. Anthropological Research Papers 36.

Altuna, J., 1996. Faunas de clima frío en la Península Ibérica durante el Pleistoceno Superior. In: Ramil-Rego, P., Fernández Rodríguez, C., Rodríguez Guitián, M., Biogeografía Pleistocena-Holocena de la Península Ibérica, 13-35. Xunta de Galicia, Santiago de Compostela.

\footnotetext{
${ }^{1}$ El lugar y modo de obtención de la muestra fueron acordados con el prof. Göran Possnert del laboratorio sueco. Para su delicada ejecución pudimos contar con la generosa ayuda del orfebre ovetense Carlos Álvarez, autor de la restauración de las cruces de los Ángeles y de la Victoria, símbolos extraordinarios del reino altomedieval de Asturias.
} 
Álvarez-Lao, D., García, N., 2010. Chronological distribution of Pleistocene cold-adapted large mammal faunas in the Iberian Peninsula. Quaternary International 212, 120-128.

Álvarez-Lao, D., Ruiz-Zapata, M.B., Gil-García, M.J., Ballesteros y Jiménez, M.,

2015. Palaeoenvironmental research at Rexidora Cave: New evidence of cold and dry conditions in NW Iberia during MIS 3. Quaternary International 379, 35-46.

Azéma, M., 2009. L’Art des cavernes en action. Tome 1: les animaux modéles. Aspect, locomotion, comportement. Éditions Errance, Paris.

Balbín-Berhmann, R., 1989. L'Art de la Grotte de Tito Bustillo (Ribadesella, Espagne). Une vision de synthése. L'Anthropologie 93, 435-462.

Barandiaran, I., 1971. La cueva de La Paloma (Asturias). Munibe 23, 255-283.

Barandiaran, I., 1967. El paleomesolítico del pirineo occidental: bases para una sistematización tipológica del instrumental óseo paleolítico. Universidad de Zaragoza, Facultad de Filosofía y Letras. Monografías Arqueológicas 3.

Barandiaran, I., 1969. Representaciones de renos en el arte paleolítico español. Pyrenae 5, 1-33.

Barandiaran, I., 1973. Arte mueble del paleolítico cantábrico. Universidad de Zaragoza. Monografías Arqueológicas, 4.

Barandiaran, I., 1988. Datation C14 de l'art mobilier magdalénien cantabrique. Bulletin de la Société Préhistorique de l'Ariége 43, 63-84.

Barandiaran, I., 1994. Arte mueble del paleolítico cantábrico: una visión de síntesis en 1994. Complutum 5, 45-79.

Barandiaran, I., 2003. Grupos homoespecíficos en el imaginario mobiliar magdaleniense. Retratos de familia y cuadros de género. Universidad del País Vasco, Vitoria-Gasteiz. Anejos de Veleia, Series Minor 21.

Bouchud, J., 1966. Essai sur le Renne et la climatologie du Paleolithique moyen et superieur. Imprimerie Magne, Perigueux.

Cabré, J., 1915. El arte rupestre en España (regiones septentrional y oriental). Comisión de Investigaciones Paleontológicas y Prehistóricas, Madrid. Memoria 1.

Castaños, P.,1980. La macrofauna de la cueva de La Paloma (Pleistoceno terminal de Asturias), en Hoyos et al. La cueva de La Paloma. Soto de las Regueras (Asturias). Excavaciones Arqueológicas en España, 67-108.

Castaños, P., 2014. Estudio de los macromamíferos del yacimiento de Santa Catalina. La cueva de Santa Catalina (Lekeitio). La intervención arqueológica. Restos vegetales, animales y humanos. Kobie. BAI 14, 331-360.

Chapa-Brunet, T, Martínez-Navarrete, M.J., 1977. Pieza inédita del arte mueble asturiano. In: XIV Congreso Nacional de Arqueología, 165-174, Zaragoza.

Corchón, M.S., 1971. Notas en torno al arte mueble asturiano. Publicaciones de la Universidad de Salamanca. Col. "Opera Minora".

Corchón, S., 1986. Arte mueble paleolítico cantábrico. Contexto y análisis interno. Centro de Investigaciones y Museo de Altamira. Ministerio de Cultura..Monografías no 16. Madrid.

Corchón, S., 1992. Representaciones de fauna fría en el arte mueble de la cueva de Las Caldas (Asturias, España). Significación e implicaciones en el arte parietal. Zephyrus 45, 35-64.
Corchón, S., Ortega, P., Rivero, O., 2015. The Magdalenian occupation of level IX of Las Caldas Cave (Asturias), Spain): A spatial approach. Quaternary International, 412, Part A. http:// dx.doi.org/10.1016/j.quaint.2015.11.051.

Crémadès, M., Bonissent, D., 1993. La représentation des variations saisonnières dans I'art parietal paléolithique. Applications au groupe des Cervidés et limites de la méthode. Paléo, Revue d'archeologie préhistorique 5, 319-331.

Delpech, F., 1983. Les faunes du Paléolithique Supèrieur dans le Sudouest de la France. Cahiers du Quaternaire 6, 1-453.

Hernández-Pacheco, E., 1922. Plaques d'ardoise et os gravés de la caverne de La Paloma en Asturias (Espagne). Revue Anthropologique 32, 338 y ss.

Hernández-Pacheco, E., 1923a. La vida de nuestros antecesores paleolíticos según los resultados de las excavaciones en la caverna de La Paloma (Asturias). Comisión de Investigaciones Paleontológicas y Prehistóricas, Madrid. Memoria 31.

Hernández-Pacheco, E., 1923b. Grabado esotérico del Magdaleniense medio de la cueva de La Paloma (Asturias). Sociedad Española de Antropología, Etnografía y Prehistoria. T. II (1), 19-22.

Hoyos-Gómez, M., Martínez-Navarrete, M.I., Chapa-Runet, T., Castaños, P., Sanchíz, F.B., 1980. La cueva de La Paloma. Soto de las Regueras (Asturias). Excavaciones Arqueológicas en España. Ministerio de Cultura, Madrid.

Moure, A., 1982. Placas grabadas de la Cueva de Tito Bustillo. Studia Archaeologica, 69, 6-21.

Obermaier, H., 1925. El Hombre Fósil. $2^{a}$ ed. CIPP, Madrid.

Pérez-Pérez, M., 1975. Algunas piezas inéditas de la cueva de La Paloma. Boletín del Instituto de Estudios Asturianos 86, 731-754.

Soubeyran, F., 1993. La vie quotiddienne des rennes entrevue dans l'art magdalenien. Bulletin de la Société historique et archéologique du Périgord 120, 229-264. 
